\title{
Corpo, mito e imaginário nos postais das praias cariocas
}

\author{
Euler David de Siqueira* \\ Denise da Costa Oliveira Siqueira**
}

\begin{abstract}
Resumo
"Cidade Maravilhosa", "capital cultural”, o Rio de Janeiro é ícone do Brasil em uma série de discursos, entre eles o turístico. As bancas de jornal da cidade exibem cartões-postais com fotos que exploram a imagem do corpo feminino na orla carioca e a mostram como imagem da cidade. A partir da análise de uma amostra intencional e não-probabilística de exemplares dessa mídia, o objetivo deste trabalho é o de estudar a relação entre o corpo e o espaço urbano na construção do imaginário sobre a cidade do Rio de Janeiro. Entre alguns dos resultados encontrados, observa-se a construção de um imaginário que reforça antigos clichês em que a cidade do Rio de Janeiro e seus personagens são apresentados como tendo uma natureza sensual, quente e festiva.
\end{abstract}

Palavras-chave: Comunicação. Imaginário. Corpo. Cartões-postais. Turismo.

\section{Body, myth and imaginary in the post cards of Rio de Janeiro's beaches}

Abstract

"Wonderful city", "cultural capital", Rio de Janeiro is an icon of Brazil in a series of speeches, among them the touristic one. Many postcards of the city show pictures that explore the image of the women body in the beaches of Rio and show it as the image of the city. From the analysis of an election of examples of this media the aim of this work is to study the relationship between the body and urban space in the construction of the imaginary about the city of Rio de Janeiro. Among the results of the study, we can find an imaginary that reinforces

* Doutor em Sociologia (IFCS/UFRJ). Pós-doutourado em Sciences Sociales no Centre d'étude sur l'actuel et le quotidien/Université Paris-Descartes/Sorbonne. Professor associado do Programa de Pós-Graduação em Ciências Sociais, Instituto de Ciências Humanas (ICH), Universidade Federal de Juiz de Fora. Juiz de ForaMG, Brasil. E-mail: euler.david@ufjf.edu.br

**Doutora em Comunicação (ECA/USP). Pós-doutourada em Sciences Sociales no Centre d'étude sur l'actuel et le quotidien/Université Paris-Descartes/Sorbonne. Professora adjunta do Programa de Pós-Graduação em Comunicação, Faculdade de Comunicação Social da Universidade do Estado do Rio de Janeiro. Rio de Janeiro-RJ, Brasil. E-mail: denise.siqueira@yahoo.com.br 
the old "cliché" where Rio de Janeiro and its inhabitants are presented as having a sensual, warm and festive nature.

Key words: Communication. Imaginary. Body. Postcards. Tourism.

\section{Cuerpo, mito e imaginario en los postales de las playas de Rio de Janeiro \\ Resumen}

"Ciudad maravillosa", "capital cultural", Río de Janeiro es uno icono de Brasil en una serie de discursos, entre ellos el turístico. Las tiendas de periódicos de la ciudad presentan tarjetas-postales con fotos que exploran la imagen del cuerpo femenino en las playas de Río y lo presentan como imagen de la ciudad. A partir del análisis de una elección de ejemplos de este medio, el objetivo de este trabajo es estudiar la relación entre el cuerpo y el espacio urbano en el imaginario de la ciudad de Río de Janeiro. Entre algunos de los resultados encontrados, está la construction de un imaginario que refuerza el viejo "cliché" de que la ciudad de Río de Janeiro y sus personajes como poseedores de una naturaleza sensual, cálida y festiva.

Palabras clave: Comunicación. Imaginario. Cuerpo. Postales. Turismo.

\section{Introdução}

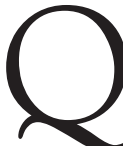

uando viaja, o turista ou o viajante busca comunicar impressões do lugar visitado por meio de relatos que podem ser feitos durante a viagem ou após o retorno: fotografias em papel ou digitais, vídeos, souvenirs e cartões-postais impressos ou digitais são alguns dos registros possíveis. Tanto para turistas quanto para viajantes, os cartões-postais parecem ser um bom meio de comunicação com aqueles que ficam, uma das muitas formas de mostrar o que se viu e conheceu, enfim, de dizer que se "esteve lá". Mas, afinal o que os postais mostram ou ocultam? Que tipo de operações levam à seleção dessas imagens fotográficas que ficarão como recordação da viagem? A partir da análise de uma amostra intencional e não-probabilística de exemplares da mídia, objetiva-se compreender o tratamento dado a relação entre o corpo e o espaço urbano na construção do imaginário sobre a cidade do Rio de Janeiro nos referidos postais.

Em grande parte, o envio e a chegada de um cartão-postal é uma forma específica de interação social. Justamente quando 
se quer comunicar ao outro o que se viu e sentiu, depara-se com imagens construídas, por exemplo, sob a forma mítica ou ideológica, imagens que não guardam nenhuma relação com a cultura sustentada por grupos sociais de uma dada localidade.

Produzido a partir de uma ou mais fotografias, o cartão-postal retrata inúmeros aspectos dos mais diferentes lugares; representa traços, elementos, partes de um todo que não pode aparecer em sua totalidade. Ele apresenta, então, um caráter totalizante e reducionista. Esse caráter está relacionado com o fato de o postal ser produto, destinado ao consumo e que, portanto, deve atrair a atenção de um publico predominantemente masculino; mas também pode estar vinculado ao seu potencial de veículo para propaganda do Estado sobre uma localidade, assumindo um papel político e ideológico.

Sua leitura é, assim, um modo de analisar como o turismo é construído a partir de imagens, sensações e informações. É também uma boa forma de pesquisar o imaginário de uma sociedade justamente porque não se constitui somente de imagens, mas é o próprio imaginário em ação. Admite-se que é constituído por mito e como tal, conta algo sobre alguma coisa; ordena e dá sentido ao mundo.

E o que os mitos-cartões-postais buscam comunicar? Nesse trabalho, procuramos mostrar como o corpo, o espaço e o turismo aparecem nos cartões-postais de praias cariocas. De imediato aparece uma questão que - talvez devido à forma como a imagem é produzida e distribuída em nossa sociedade - não recebe maiores críticas da parte dos analistas sociais: trata-se de romper com a naturalização a respeito de qual corpo, como e em que praias ele aparece. Em primeiro lugar, não se trata de um corpo qualquer mas, sim, de corpos femininos, jovens e "em forma", segundos os padrões morais vigentes em nossa sociedade (GOLDENBERG, 2002). Em segundo lugar, é um corpo construído segundo técnicas orientadas de marketing e publicidade. Ou seja, não se trata de um corpo flagrado em suas formas sociais "normais". Em terceiro, não é qualquer praia que serve de suporte para qualquer corpo. São algumas praias principalmente da Zona Sul carioca. Em toda a amostra de cartões-postais adquiridos em bancas de jornal em diferentes 
pontos da cidade, somente as praias de Ipanema, Copacabana, Leblon e, na Zona Oeste, a praia da Barra da Tijuca, aparecem de forma explícita. Uma parte da amostra apresenta corpos femininos associados a pontos turísticos tradicionais como o Corcovado e o Pão-de-Açúcar ou ainda a outras praias não identificadas.

A partir de uma perspectiva antropológica, lançamos mão de uma metodologia qualitativa a fim de interpretar uma dada realidade social. Utilizamos uma amostragem não probabilística por escolha. Adquirimos doze cartões-postais que foram divididos em dois subgrupos: no primeiro, com oito cartões, as praias de Ipanema, Leblon, Barra da Tijuca e Copacabana são identificadas; no segundo, com quatro cartões, tem-se a presença de corpos em praias não identificadas assim como associados a outros pontos turísticos tradicionais.

É importante ressaltar que escolhemos um tipo de postal para analisar, aquele em que o corpo feminino aparece como imagem da cidade. Há, no entanto, outros tipos: postais que mostram a "natureza", que retratam monumentos e, até, que mitificam favelas, apresentando-as não como problema social, econômico e habitacional, mas sim, como ponto "pitoresco", exótico. Aqui, para efeitos de análise, selecionamos como objeto de pesquisa postais que parecem veicular um olhar masculino/"machista" sobre o corpo da mulher nas praias cariocas.

\section{Imagem e imaginário}

Para o antropológo francês Marc Augé (1998, p.31), “as imagens podem servir para tudo". Imagens operam no campo do simbólico, das representações. São construções mentais, possibilitadas pela percepção dos objetos contidos nos mundos físico, social e cultural. Desse modo, a percepção do mundo exterior e objetivo - mas também interior e subjetivo - é uma das condições da construção das imagens e de sua dinâmica, o imaginário. As imagens guardam, portanto, alguma relação do mundo exterior com as consciências dos sujeitos. Não são simples cópias dos dados percebidos por nossos sentidos ou reproduções fiéis dos objetos percebidos da realidade. 
Em Filosofia da caixa preta: ensaios para uma futura filosofia da fotografia, Vilém Flusser escreve que imagens "são superfícies que pretendem representar algo. $\mathrm{Na}$ maioria dos casos, algo que se encontra lá fora no tempo e no espaço. As imagens são, portanto, resultado do esforço de abstrair duas das quatro dimensões de espaço-tempo, para que se conservem apenas as dimensões do plano" (2002, p.07). As imagens têm, portanto, um duplo caráter: material e representativo.

Imagens são, grosso modo, a elaboração secundária (discurso de segunda ordem) de um primeiro contato com a realidade (discurso de primeira ordem). Para Laplantine e Trindade (1997, p.10) imagens também podem ser definidas como

construções baseadas nas informações obtidas pelas experiências visuais anteriores. Nós produzimos imagens porque as informações envolvidas em nosso pensamento são sempre de natureza perceptiva. Imagens não são coisas concretas mas são criadas como parte do ato de pensar. Assim, a imagem que temos de um objeto não é o próprio objeto, mas uma faceta do que nós sabemos sobre esse objeto externo.

As imagens possuem um caráter dinâmico. O imaginário, nesse sentido, é a própria dinâmica das imagens. Assim, as imagens "construídas no universo mental, superpõem-se, alteram-se, transformam-se" (LAPLANTINE; TRINDADE, 1997, p.10). Conforme Flusser (2002, p.8), "o caráter mágico das imagens é essencial para a compreensão das suas mensagens”. Esse caráter mágico permite que o tempo linear, baseado em relações de causalidade, seja rompido em nome de um tempo mágico circular doador de significados. Nas palavras de Flusser (2002, p.8), "no tempo linear, o nascer do sol é a causa do canto do galo; no circular, o canto do galo dá significado ao nascer do sol, e este dá significado ao canto do galo". Imagens e imaginário estão em perpétua transformação.

De fato, realidade e real não se confundem. Considerado em si mesmo, o mundo objetivo não pode ser conhecido sem que um sujeito o interprete segundo uma cultura que o habilite a "ler" a realidade. Somente quando submetido às grades de pensamento, às lentes culturais próprias de uma dada cultura, é o que o mundo 
se torna "fenômeno", tornando-se inteligível aos homens. Assim, o imaginário guarda proximidade com as representações sociais, já que as imagens também são representações coletivas. Para Fernando Brumana (1983, p.29), "o conjunto das representações de uma sociedade concreta poderia dar-nos o mapa daquilo que pode ser pensado e praticado, mapa do qual as instituições seriam a atualização, a sua constatação palpável”.

Nesse nível, a cultura permite-nos pensar o pensamento de um grupo, de uma sociedade, de uma comunidade, assim como suas práticas, atos e gestos. Aqui mesmo buscamos situar o fenômeno da representação, da construção do imaginário no plano da obra coletiva. É dessa forma que as representações coletivas

são o produto de uma imensa cooperação que se estende não apenas no espaço, mas no tempo; para fazê-las, uma multidão de espíritos diversos associaram, misturaram, combinaram suas idéias e sentimentos; longas séries de gerações acumularam aqui sua experiência e seu saber. Uma intelectualidade muito particular, infinitamente mais rica e mais complexa do que a do indivíduo, está aqui, portanto, como que concentrada (DURKHEIM, 1973, p.518).

Fazendo seu o pensar de Durkheim, Brumana (1983, p.27), enfatiza ainda o princípio de irredutibilidade da consciência coletiva à consciência individual: "As representações coletivas são irredutíveis às psiques individuais”. Marc Augé (1997, p.63), por sua vez, enfatiza que entre o imaginário coletivo e o individual há uma poderosa dialética, pois, "o imaginário e a memória coletivos (IMC) constituem uma totalidade simbólica em referência à qual um grupo se define e por meio da qual ele se reproduz de um modo imaginário ao longo das gerações”.

Dessa forma, o imaginário coletivo e o individual mantêm relações estreitas, ainda que o primeiro não seja obra do segundo e o segundo somente se constitua tendo o primeiro como condição de operação. As representações coletivas e o imaginário não são criações livres, independentes dos indivíduos. Estão na fronteira do mundo dos vivos e dos mortos, já que herdamos instituições sociais criadas muito antes de nosso nascimento. $\mathrm{O}$ conjunto de representações sociais de uma sociedade não é nem o resultado 
da apreensão empírica do mundo nem tampouco a expressão de elementos inatos ou naturais da mente humana. É dessa forma que as representações sociais são constituídas por categorias de pensamento. Nas palavras de Durkheim (1973, p.513)

Existe, na base de nossos julgamentos, um certo número de noções essenciais que dominam toda a nossa vida intelectual; são aquelas que os filósofos, desde Aristóteles, chamam de categorias do entendimento: noções de tempo, de espaço, de gênero, número, causa, substância, personalidade, etc. Elas correspondem às propriedades mais universais das coisas. Elas são como quadros rígidos que encerram o pensamento (...) São como a ossatura da inteligência.

As categorias de pensamento, coletivas e sociais, não são nem oriundas de uma perspectiva apriorística - isto é, elas não são categorias inatas, condições de nossas mentes, nem, do ponto de vista metafísico, algo plantado por um deus. Por sua vez, não seria o indivíduo, pura e simplesmente, o artífice das categorias de pensamento. Ou seja, a perspectiva a posteriori, fruto da experiência, também é descartada por Durkheim. Categorias de pensamento são representações sociais, coletivas; são estados de uma consciência de consciências, são históricas, "jamais estão fixadas sob uma forma definida; fazem-se, desfazem-se e refazemse ininterruptamente; mudam segundo os lugares e os tempos" (DURKHEIM, 1973, p.517).

Em nosso ato de pensar, o que percebemos, a realidade, é submetida a um processo de interpretação, passando à condição de real. Assim, a realidade consiste no fato de que essa pessoa, os objetos sociais e naturais (outras pessoas) e o mundo da natureza existem em si mesmos, independentes da nossa presença e dos significados que atribuímos a eles.

O real é a realidade ordenada e organizada por nossos sistemas de pensamento ou pelo conjunto das categorias de pensamento coletivas de uma dada sociedade. Nesse sentido, "o real é a interpretação que os homens atribuem à realidade. $\mathrm{O}$ real existe a partir das idéias, dos signos e dos símbolos que são atribuídos à realidade percebida" (LAPLANTINE; TRINDADE, 1997, p.12).

Contudo, entre idéias, imagens e símbolos, há diferenças. Enquanto a imagem se identifica com seu objeto referente, o símbolo, 
devido a sua arbitrariedade, pode romper com essa relação, indo para além do objeto que opera como significante. Segundo Laplantine e Trindade (1997, p.13), "tanto a imagem como o símbolo constituem representações” e essas "não significam substituições puras dos objetos apresentados na percepção, mas são, antes, reapresentações, ou seja, a apresentação do objeto percebido de outra forma, atribuindo-lhe significados diferentes, mas sempre limitados pelo próprio objeto que é dado a perceber".

Há algo presente nas imagens e em seu desenvolvimento, o imaginário, que não está presente na realidade. Se por um lado a imagem busca representar algo que se encontra no tempo-espaço, a imaginação "é a capacidade de fazer e decifrar imagens" (FLUSSER, 2002, p.07).

Segundo o semiólogo francês Roland Barthes (1980), o imaginário é o signo, uma relação de significância. Ou seja, uma relação que se estabelece entre um significante e um significado.

O imaginário se apodera das imagens apreendidas pelos sujeitos, alterando-as de tal forma que "ao libertar-se do real que são as imagens primeiras, pode inventar, fingir, improvisar, estabelecer correlações entre os objetos de maneira improvável e sintetizar ou fundir essas imagens" (BARTHES, 1980, p.27). O imaginário possui a dinâmica de fazer mudar o real. E isso não implica na exclusão total do real, senão na manutenção de uma identidade com ele.

Marc Augé enfatiza que quando os meios de comunicação de massa - podemos incluir aqui os cartões-postais - operam como mediadores no lugar das mediações simbólicas, tal operação "contém em si uma possibilidade de violência” (AUGÉ, 1997, p.22). A violência irromperia quando a interação dialética entre a identidade e a alteridade, entre o eu e o outro, fosse rompida. Para Augé, as práticas rituais, mediadoras simbólicas, criam a identidade, mas também a alteridade, afinal, como esclarece o autor (1997, p.19) "no plano etnológico, seria possível mostrar que toda atividade ritual tem por finalidade a produção de identidade por meio do reconhecimento de alteridades".

\section{Cartão-postal: técnica, signo e mito}

Arte e técnica, registro e memória, invenção ou imaginação, a fotografia é uma das mídias contemporâneas mais populares. Está 
presente nos documentos de identificação individual, nos meios de comunicação impressos e on-line assim como nas paredes de museus. Há muito a fotografia desobrigou-se de ser instrumento para "registrar" a realidade: a arte a utiliza de forma simbólica enquanto instituições que deveriam utilizá-la como registro do real, acabam por manipulá-la, reconstrui-la.

Na sociedade contemporânea, voraz no consumo não só de objetos ditos "concretos", mas principalmente de imagens, a fotografia desempenha um papel importante e, com ela, a técnica assume posição central no processo de produção e reprodução, colaborando para a valorização da dimensão visual.

A relação superficial entre indústria cultural e consumo de objetos culturais se explica na medida em que no contexto da "indústria cultural" ou da comunicação de massa, o estímulo ao consumo promove a necessidade de posse de objetos culturais, o que favorece sua cópia em grande escala. Tomando emprestado o pensamento de Benjamin (1993), pode-se dizer que o objeto de arte quando submetido às técnicas da indústria cultural que o reproduzem com fins de transformação em mercadoria, perde sua "aura".

Dessa forma, "A imagem fotográfica capta o instante, o momento cotidiano que pode ser produzido, arrumado (como na pintura) ou espontâneo. Essa espontaneidade a pintura não pode captar. Somente a fotografia tem a velocidade necessária" (SIQUEIRA, 1999, p.61). Nos cartões-postais dos corpos de mulheres nas praias da orla carioca, as fotografias expostas mostram imagens construídas, produzidas profissionalmente para parecer espontâneas. Mostram cotidianos arrumados, como nos retratos da fase pré-fotografia, quando a pintura tinha obrigação de retratar o "real", mas um real sempre em sua melhor forma, conivente com um determinado ponto de vista.

Nos postais estudados tanto o signo, quanto algo do universo mitológico estão presentes. Assim, os cartões - como as fotografias, de uma forma geral - podem servir de suporte à fala mítica.

Mas, o cartão-postal é signo ou significante? O lingüista suíço Ferdinand de Saussure (1995, p.81), define signo como 
a combinação do conceito e da imagem acústica: mas, no uso corrente, esse termo designa geralmente a imagem acústica apenas, por exemplo uma palavra (arbor etc.). (...) Propomo-nos a conservar o termo signo para designar o total, e a substituir conceito e imagem acústica respectivamente por significado e significante.

Entre o significado, o conceito, elemento um pouco mais abstrato, nos dizeres de Saussure, e o significante, a imagem acústica, também esse uma entidade psíquica, há uma relação, um vínculo. Esse vínculo não encerra nenhuma relação natural entre o significado e o significante. É assim que para Saussure, o signo é arbitrário (1995). No entanto, se Saussure atesta o caráter arbitrário do signo, reduz a arbitrariedade do símbolo. Para esse último, há entre o significado e o significante um vínculo que impede que qualquer significado/conceito, possa ter qualquer significante. Como exemplo simples dessa relação, para representar simbolicamente o café, não se pode ter como representante um abacaxi.

Roland Barthes, também admitia, tal qual Saussure, o estudo da semiologia como uma relação entre dois termos, um significante e um significado. Contudo, Barthes adiciona um terceiro elemento a essa relação - o próprio signo - fruto da relação entre o significado e o significante. Se o significante para Barthes é vazio, o signo é pleno, repleto de sentidos. Assim, "no plano da análise, não posso confundir as rosas como significante e as rosas como signo: o significante é vazio, o signo pleno, é um sentido" (BARTHES, 1980, p.135).

Como todo mito, o cartão-postal busca ordenar uma dada realidade; busca explicar, de maneira coerente, algo que a princípio se coloca como desordenado e caótico. Nos cartões-postais estudados, o signo está presente, porém, há mais neles. Para Barthes (1980, p.136),

No mito, pode encontrar-se o mesmo esquema tridimensional de que acabei de falar: o significante, o significado e o signo. Mas o mito é um sistema particular, visto que ele se constrói a partir de uma cadeia semiológica que existe já antes dele: é um sistema semiológico segundo. O que é signo (isto é, totalidade associativa de um conceito e de uma imagem) no primeiro sistema, transforma-se em simples significante no segundo. É necessário recordar, neste ponto, que as matérias-primas da fala mítica (língua propriamente dita, fotografia, pintura, cartaz, rito, objeto etc.), 
por mais diferentes que sejam inicialmente, desde o momento em que são captadas pelo mito, reduzem-se a uma pura função significante: o mito vê nelas apenas uma mesma matéria-prima; a sua unidade provém do fato de serem todas reduzidas ao simples estatuto de linguagem.

Se vamos considerar os cartões-postais que nos falam sobre os corpos de mulheres nas praias cariocas como mito, então, estamos tratando de um sistema de signos que opera como significante para, logo em seguida, constituir novos signos. Em poucas palavras, o mito é um sistema em que há dois signos. Segundo Barthes (1980, p.139),

o significante do mito apresenta-se de uma maneira ambígua: é simultaneamente sentido e forma, pleno de um lado, vazio de outro. Enquanto sentido, o significante postula já uma leitura, apreendo-o com os olhos, ele tem uma realidade sensorial (ao contrário do significante lingüístico, que é de ordem puramente psíquica), tem uma riqueza.

Se o significante do signo é vazio de sentido, no mito, seu sentido é dúbio. Sabemos que ele não é vazio como o significante, pois é signo num primeiro sistema e, assim, pleno. Mas, quando transformado em mito, o significante, que já se encontra carregado de um primeiro sistema de sentido anterior, é esvaziado nesse segundo momento. A forma como o mito adquire sentido é da ordem do conceito. Assim, segundo Barthes, "através do conceito, toda uma história nova é implantada no mito” (1980, p.140).

A tarefa do mito é a de mediar, instaurar o contato entre o que é estranho e o já conhecido. Mas se o mito pode consolar, também tem a capacidade de ludibriar. Roland Barthes, em Mitologias, mostra o mito como uma fala aparentemente despolitizada, mas que carrega um conjunto ideológico - motivo forte pelo qual os meios de comunicação se apropriam dele.

O mito dá conta de uma série de situações e está presente entre nós, seja nas narrativas orais, nos discursos midiáticos - como no dos telejornais - ou mesmo em cartões-postais para turistas. Assim,

O mito também "serve", "funciona" para justificar o que é inconsciente ou transcendente (...) $\bigcirc$ mito não pode ser identificado como mentira. $\bigcirc$ mito é uma forma de preservar e representar valores, funcionando dialeticamente 
de modo ampliado, antecipado, esclarecedor ou ocultante. De qualquer forma, o mito comunica, não mente e está presente no teatro, na dança, no circo, na literatura, na telenovela e até no jornalismo, no que se chama de notícia (SIQUEIRA, 1999, p.80).

Nos discursos dos meios de comunicação de massa, a informação é deslocada para um segundo plano em função da ênfase nos elementos emotivos, próprios do campo do imaginário. Isso ocorreria devido ao fato de ser o mito um registro do imaginário e que, como tal, precisaria de interpretação.

\section{Corpo, praia e turismo: identidade e alteridade}

Técnica, signo e mito, o postal é uma mídia que transmite uma série de mensagens. $\mathrm{O}$ estudo desse instrumento-mídia pode desvelar falas implícitas nas imagens exibidas.

De um total de doze cartões-postais da amostra estudada, oito identificam explicitamente praias da orla da Zona Sul carioca, como Copacabana e Ipanema e quatro mostram praias sem nomeá-las. Em todos eles corpos de jovens banhistas aparecem associados a praias, à cidade ou a pontos turísticos. São espaços que ocupam lugar de destaque no imaginário da cidade do Rio de Janeiro, do Brasil. Resumindo, esses cartões-postais tratam da dimensão corporal, espacial e temporal, associando o Rio de Janeiro a um apelo sensual.

A título de classificação, numeramos os cartões em ordem crescente ao mesmo tempo em que adotamos uma nomenclatura específica. Assim, temos os cartões referentes a Copacabana como C1, C2, C3, C4, C5 e C6 e os da praia de Ipanema como I1 e I2.

Tendo a praia de Copacabana ao fundo, com prédios, hotéis, e o forte de Copacabana, quatro jovens aparecem de costas no cartão C1. Em função da grande quantidade de banhistas, especula-se ser um fim de semana ou feriado. Das quatro "banhistas”, duas estão de pé, à esquerda de quem olha o cartão. Elas parecem conversar, enquanto as outras se encontram deitadas diretamente sobre a areia. As duas "banhistas" deitadas estão de cabelos soltos, enquanto as duas outras os têm presos. As quatro 
estão desacompanhadas de figuras masculinas. Diferentemente dos demais banhistas do cartão, que compõem parte do cenário da foto, as quatro banhistas em primeiro plano têm determinadas partes de seus corpos em explícito destaque: costas e nádegas. Apesar da ausência de datas nos cartões, este parece ser o mais antigo da amostra, a foto datando dos anos 80 . Isso fica claro na indumentária: as moças vestem biquinis modelo asa delta, fashion nos verões da década de 80 .

No Cartão C2, quatro jovens de biquini aparecem em primeiro plano, tendo ao fundo inúmeros prédios de Copacabana. As duas louras e duas morenas, caminham pelo calçadão de Copacabana em direção à praia do Leme. Mais uma vez, as banhistas estão de costas, com cabelos longos e soltos, deixando à mostra a parte de trás de seus corpos: costas, pernas e nádegas. Em C2, assim como em $\mathrm{C} 1$, nenhuma das banhistas está acompanhada de homens ou crianças. $\mathrm{O}$ que pode sugerir que são solteiras, sem filhos, prontas para um relacionamento. C2 sugere ainda que as banhistas são observadas mas não se dão conta disso, da mesma forma que todos os que se encontram na areia da praia. A sua aparição na foto parece querer revelar um "flagrante" de um dia normal na praia de Copacabana. Se em C1 havia quatro banhistas na areia da praia posando para a foto, em C2, as banhistas criam uma primeira oposição por estarem no calçadão, sem se misturar com os demais.

No cartão C3, as mesmas jovens que aparecem em C2 estão na areia da praia, deitadas sobre cangas. Não é difícil identificálas apesar de seus rostos não aparecerem: a cor dos biquinis, assim como dos cabelos e os próprios corpos, são os mesmos. Em C3, no entanto, não há nenhuma referência espacial capaz de dar ao leitor qualquer ponto de referência que possa identificar em que praia estão. Há somente quatro corpos femininos em um dia ensolarado na praia. Como em C1 e C2, C3 apenas mostra explicitamente a parte de trás dos corpos das mulheres, notadamente as nádegas. Embora não seja possível identificar a praia, a imagem é completada com os dizeres Praia de Copacabana - Rio de Janeiro - Brasil.

No quarto cartão, mais quatro jovens aparecem caminhando lado a lado nas areias da praia de Copacabana. Em C4, mais uma 
vez, as jovens andam de costas para o leitor exibindo costas, pernas e nádegas. O cenário que compõe o cartão é formado de um lado, pelo mar, azul, com pequenas ondulações, de outro, por prédios que se estendem por toda a avenida Atlântica, do Leme ao final da praia de Copacabana. Ao centro do cartão, na parte inferior, aparecem os dizeres Praia de Copacabana, Rio de Janeiro, RJ, Brasil.

Em C5, as mesmas jovens de C4 estão deitadas na areia sobre uma mesma canga, mais uma vez sem que seus rostos sejam revelados. A ênfase do cartão recai, novamente, sobre pernas, nádegas e costas. Os pés são cortados da foto, com exceção da jovem à direita de quem vê o cartão, que tem uma parte de seu pé esquerdo fotografado. Não há nenhum ponto de referência que possibilite identificar a praia, embora na parte inferior e central, apareçam os dizeres: Praia de Copacabana, Rio de Janeiro, RJ, Brasil.

O sexto cartão desse primeiro subgrupo distingue-se dos anteriores por conter cinco fotos no lugar da imagem central dos demais. Elas retratam, no sentido horário: quatro moças de biquini caminhando no calçadão de Copacabana e vistas aéreas da praia de Copacabana, do Estádio do Maracanã, Cristo Redentor e Pão de Açúcar. C6 diferencia-se de todos os cartões por colocar lado a lado o corpo sensual, quase nu, aproximado de outros pontos turísticos. Enquanto as jovens, andando de costas para o leitor, chamam a atenção para determinadas partes de seus corpos, nas demais fotografias, há imagens feitas a partir de um ponto distante, sem que nada chame a atenção para um ponto específico. Com as jovens de biquini é diferente: se tudo mais é indiferente (prédios, praia, areia, mar, demais banhistas, avenida), são seus corpos que não podem passar despercebidos. Por fim, os nomes Rio de Janeiro e Brasil aparecem no centro do cartão.

No primeiro cartão que faz referência à praia de Ipanema, aparecem quatro banhistas mais uma vez, trajando biquinis, deitadas na areia sobre cangas. Se em C3 quatro mulheres apareciam ao centro do cartão dos pés à cabeça, em I1, as mesmas quatro banhistas são fotografadas de lado. É importante ressaltar que I1 reproduz as jovens de C2 e C3, agora mostradas lateralmente. Por meio da observação atenta da areia presente em seus pés e da forma como suas pernas estão cruzadas, assim como a ordem em 
que elas aparecem nos cartões e das marcas deixadas na areia, I1 e C3 mostram a mesma praia que não pode ser identificada. Pode ser Ipanema, Copacabana ou outra praia qualquer. As marcas da cidade, antes presentes em C1 e C2, desaparecem para dar lugar somente aos corpos estendido sobre a areia, ressaltando costas, nádegas e pernas. O corpo, dessa forma, é inscrito sobre a praia, demarcando um espaço que dá identidade à indistinção da areia.

I2 é similar à C6 na forma: um cartão com múltiplas fotos, a da praia de Ipanema maior e em destaque, mostrando quatro moças deitadas sobre uma canga na areia. Em segundo plano estão outros banhistas. As outras três imagens são tomadas aéreas das praias da Barra da Tijuca, do Leblon e de Copacabana. Diferentemente das demais fotografias de I2, somente a da praia de Ipanema exibe jovens de biquini, deitadas sobre cangas. Compondo a paisagem, observam-se outros banhistas que parecem indiferentes ao que se passa com as jovens, com exceção de uma mulher e sua filha que estão de frente para as jovens. $\mathrm{O}$ olhar de ambas parece denunciar a farsa que se monta na areia. Em oposição às fotografias das demais praias mostradas no mesmo cartão, somente a da praia de Ipanema focaliza o corpo.

\section{A não-identidade da praia e do corpo}

A segunda série, com quatro cartões, apresenta imagens de mulheres sozinhas tendo, como pano fundo, paisagens de praias. Para efeitos metodológicos, ordenaram-se os cartões como P1, P2, P3 e P4.

No primeiro cartão, P1, observa-se, em primeiro plano, uma jovem de pé, de costas para o leitor. Sozinha na praia, ela está quase de lado, com seus joelhos levemente inclinados. Ao contrário dos demais cartões que fazem referência à praia de Copacabana e Ipanema, não possibilita que se identifique nenhuma das praias da orla da cidade do Rio de Janeiro. Não há como saber em qual praia a jovem se encontra. Trajando uma pequena tanga, sem a parte superior do biquini, a jovem de P1 veste um vestido leve (que está sendo tirado ou posto?) enrolado à altura da cintura. Como nos demais cartões da série C, P1 não mostra nenhum detalhe de 
seu rosto. Importa assinalar é a sua nudez parcial em uma praia (pública?), aparentemente deserta, sem nenhuma pessoa ou sinal de construção à vista. Em P1, não há nenhuma informação escrita na parte frontal do cartão que possibilite a identificação da praia. No verso, há a inscrição Rio de Janeiro.

O próximo cartão, P2, mostra uma imagem que sugere uma praia também deserta. P2 mostra a mesma jovem de P1 agora sentada sobre as pernas, em uma tomada lateral e de costas. Da mesma forma que em P1, em P2 a jovem está sem a parte superior do biquini. Seus seios não aparecem frontalmente, seu rosto também não é mostrado. Se no postal anterior ela sugere que vai tirar o vestido, nesse ajeita a tanga (vai tirá-la?). Em P2, também chama a atenção o fato de se ter um corpo jovem e belo afastado das praias localizadas no espaço urbano mais denso. Ainda em relação a P2, abaixo das pernas da morena que esconde seu rosto, aparece simplesmente a palavra Rio, grafada de forma que as letras finais $(i$, o) pareçam um Sol brilhando, fazendo alusão a um tempo quente e ensolarado.

Em P3 surge mais uma vez a jovem bronzeada, agora com biquini completo sentada à beira do mar, divertindo-se na água. Em P3, é possível identificar a jovem de P1 e P2 pela cor da pele, o comprimento do cabelo e o biquini. Contudo, neste exemplo, a moça além de deixar seu rosto visível em um ângulo lateral, também está sorrindo. Apenas no cartão C1, um dos mais antigos, datando provavelmente da década de 1980, uma das mulheres, de pé, está sorrindo. Em P3, temos a certeza de que a mulher do postal está em uma praia, mas não sabemos qual. Na parte inferior do postal, aparece o nome Rio de Janeiro por inteiro.

$\mathrm{O}$ último cartão, P4, possui características peculiares. Ao contrário dos demais da amostra, nele a banhista não se encontra na praia, mas sim, no alto de um ponto elevado da cidade. Ela assume simbolicamente a posição de um dos atrativos mais significativos da cidade do Rio de Janeiro: o Cristo Redentor. Nesse breve momento, congelado no cartão-postal P4, o gesto do Cristo Redentor é fundido ao corpo, feminino, bronzeado, sumariamente vestido, profano. Sagrado e profano parecem coincidir no corpo bronzeado da banhista de cabelos louros, de braços abertos, de costas, sobre 
a baía da Guanabara. Longe das praias, ainda que de frente para o mar, mas agora em uma posição sagrada, a jovem de biquini se aproxima do céu através de seu gesto. Ela é, simbolicamente, a própria estátua do Cristo Redentor. Como ler o gesto, a posição do corpo e o que é mostrado desse corpo? O corpo da banhista encarnaria uma pretensa hospitalidade sensual, típica do carioca? Seu corpo, coberto apenas por um biquini quer revelar algo a mais do que a estátua do Cristo vestindo um túnica longa que cobre todo o corpo? O que diz a banhista aos turistas: bem-vindos todos aqueles que chegam à cidade onde, do alto de cada morro, estamos de braços abertos aguardando por sua chegada? É interessante observar ainda que não vemos seu rosto e não sabemos qual a sua expressão no momento da foto. Por que ser mostrada de costas, fazendo aparecer suas costas, coxas e nádegas é mais importante do que de frente, mostrando rosto, seios e barriga? Haveria alguma relação cultural entre chamar a atenção para as nádegas das banhistas e o monumento às nádegas da mulata brasileira na Praça da Apoteose, no Sambódromo?

\section{Considerações finais}

Nos cartões-postais de praias analisados ganham destaque certas partes do corpo feminino. Mais do que isso, a forma como os corpos aparecem revela técnicas corporais no que elas têm de mais fundamental: são tradicionais e eficazes (MAUSS, 1974). Nos gestos e poses em que as jovens aparecem, mais do que corpos soltos no espaço da praia, tem-se formas que são próprias de cada sociedade (MAUSS, 1974). De um modo geral, as "banhistas" têm suas costas, pernas e nádegas ressaltadas em detrimento da parte frontal do corpo. Somente em dois cartões - dos doze da amostra - partes de seus rostos são revelados. E mesmo quando parte de seus rostos aparecem, não se pode encarar as banhistas de frente. Assim, as fotografias dos cartões-postais revelam não só um conjunto de técnicas corporais, como também apresentam recorrências estruturais, sinal característico do mito. Como escreveu Barthes (1980, p.141), "é a insistência num comportamento que revela a sua intenção" . É essa intenção, presente recorrentemente na forma 
como os corpos são mostrados, em que lugar e em que tempo, que possibilita ir além de uma primeira impressão mais imediata.

De um ponto de vista relacional, costas, pernas e nádegas mostradas nos cartões se opõem ao rosto e peito, ocultos. Não se trata de uma oposição excludente, senão complementar e hierárquica. Nos postais analisados, a dimensão de trás do corpo engloba as demais dimensões (parte frontal, parte superior) tidas como hierarquicamente superiores nos demais espaços e momentos da vida social. Nos documentos de identidade, por exemplo, é o rosto, de frente, que identifica o indivíduo frente às autoridades legais; é de frente para outra pessoa que se fala quando se quer transmitir alguma mensagem importante. No entanto, em momentos não oficiais, de lazer, de Carnaval, essa hierarquia é invertida: ao invés da parte frontal do corpo ou da superior (cabeça/razão/ intelecto), o que é valorizado é o "bumbum”. Nesse instante, se destaca a dimensão informal do corpo, marginal, que se inscreve e escreve códigos distintos daqueles que operam do Estado - formal/ oficial - para os indivíduos.

Desse modo, a ênfase no corpo feminino desnudo como representação das praias da cidade busca mostrar o Rio de Janeiro como um local hospitaleiro, quente e nitidamente sensual. A dimensão sexual aparece de forma explícita como um tipo de discurso turístico que faz movimentar o imaginário do turista que já traz expectativas sobre quem são aqueles corpos caminhando na praia. Não é o único discurso e talvez não seja o dominante. É conservador e machista, na medida em que reduz a mulher a um objeto sensual a ser "consumido" pelo turista, mas revela um certo tipo de imagem da cidade constitutivo do imaginário turístico.

\section{REFERÊNCIAS}

AUGÉ, Marc. A guerra dos sonhos. Campinas: Papirus, 1997.

. Não-lugares: introdução a uma antropologia da supermodernidade.

Campinas: Papirus, 1994.

BARTHES, Roland. O grão da voz. Rio de Janeiro: Francisco Alves, 1995. 
. Mitologias. 4. ed. São Paulo: Difel, 1980.

BENJAMIN, WALTER. A obra de arte na era de sua reprodutibilidade técnica. In: ___. Magia e técnica, arte e política: ensaios sobre literatura e história da cultura. 6.ed. São Paulo: Brasiliense, 1993. p.165-196. (Obras escolhidas, v.1)

BRUMANA, Fernando. Antropologia dos sentidos: introdução às idéias de Marcel Mauss. São Paulo: Brasiliense, 1983.

DURKHEIM, Emile. As formas elementares da vida religiosa. São Paulo: Abril, 1973, p. 505-550. Col. Os pensadores.

FLUSSER, Vilém. Filosofia da caixa preta: ensaios para uma futura filosofia da fotografia. Rio de Janeiro: Relume Dumará, 2002.

GOLDENBERG, Mirian, RAMOS, Marcelo Silva. Nu e vestido: dez antropólogos revelam a cultura do corpo carioca. Rio de Janeiro: Record, 2002. p.19-40.

LAPLANTINE, TRINDADE. O que é imaginário. São Paulo: Brasiliense, 1997.

MAUSS, Marcel. As técnicas corporais. In: ). Sociologia e antropologia. São Paulo: Edusp, 1974. v. II. p. 209-234.

SAUSSURE, Ferdinand de. Curso de lingüística geral. 20. ed. São Paulo: Cultrix, 1995.

SIQUEIRA, Denise da Costa O. A ciência na televisão: mito, ritual e espetáculo. São Paulo: AnnaBlume, 1999.

. Corpo, comunicação e cultura: a dança contemporânea em cena. Campinas: Autores Associados, 2006. 